\title{
Effect of methanol as PCA in AlCoCrFeMnNi high-entropy alloy.
}

M.A. Ruiz-Esparza-Rodriguez ${ }^{1}$, C.G. Garay-Reyes ${ }^{1}$, I. Estrada-Guel ${ }^{1}$, J.M. Mendoza-Duarte ${ }^{2}$ and R. Martínez-Sánchez ${ }^{3}$

${ }^{1}$ Centro de InvestigaciónenMaterialesAvanzados (CIMAV), Laboratorio Nacional de Nanotecnología, Miguel de Cervantes No. 120, CP 31136, Chihuahua, Chih., México., Chihuahua, Chihuahua, Mexico, ${ }^{2}$ Centro de InvestigaciónenMaterialesAvanzados (CIMAV), Laboratorio Nacional de Nanotecnología, Miguel de Cervantes No. 120, CP 31136, Chihuahua, Chih., México., United States, ${ }^{3}$ Centro de InvestigaciónenMaterialesAvanzados (CIMAV) Laboratorio Nacional de Nanotecnología, Miguel de Cervantes No. 120, CP 31136, Chihuahua, Chih., México., Chihuahua, Chihuahua, Mexico

A process control agent (PCA) is critical in the powder metallurgy process since it regulates the internal processes of the mechanical alloying (fracturing and cold welding) [1]. On the other hand, high-entropy alloys are made of five or more metallic elements, so choosing a PCA is vital since the sintered material's properties depend on its optimal performance during mechanical alloying [2]. In this case, methanol's effect as PCA on the distribution of particle size, crystalline structure, microstructure, and oxidation in the alloyed powders in an AlCoCrFeMnNi high-entropy alloy system was studied.

$\mathrm{Al}, \mathrm{Co}, \mathrm{Cr}, \mathrm{Fe}, \mathrm{Mn}$, and Ni powders were alloyed by $10 \mathrm{~h}$ in a high-energy mill using methanol as PCA. Subsequently, the powders were compacted at a pressure of $1.56 \mathrm{GPa}$ for $5 \mathrm{~min}$, and green samples were sintered at $1200{ }^{\circ} \mathrm{C}$ for 3 hours in a sealed quartz tube under vacuum. The characterization was carried out in two stages. The first one comprises the alloyed powders obtained, where the particle size distribution (DLS technique), oxygen quantification (chemical analysis), morphology, and microstructure (SEM) were evaluated. The second stage consists of studying the microstructure, structure (XRD/TEM), and oxygen quantification (TGA) of the sintered samples.

Figure 1, a) shows a bimodal distribution in the particle size, which indicates that during mechanical alloying, the fracture process predominant over the cold-welding process. This behavior allows inferred particular influence of oxygen content over such processes and the microstructure (figure $1 \mathrm{~b}$ ). Concerning microstructure, it is evident that the diffusion process was inefficient since $\mathrm{Co}$ and $\mathrm{Cr}$ distribution were not homogenized in the microstructure; also, Al2O3 particles are observed. Figure 2 shows samples sintering at $1200^{\circ} \mathrm{C}$; such samples present a weight gain(a), indicating significant oxidation in the samples. The formation of a larger transformed fraction of particles of A12O3 is observed in figure 2 b). Finally, a biphasic microstructure ( $\mathrm{BCC}+\mathrm{FCC}$ ) was identified according to the diffractograms (figure $2 \mathrm{c}$ ). 

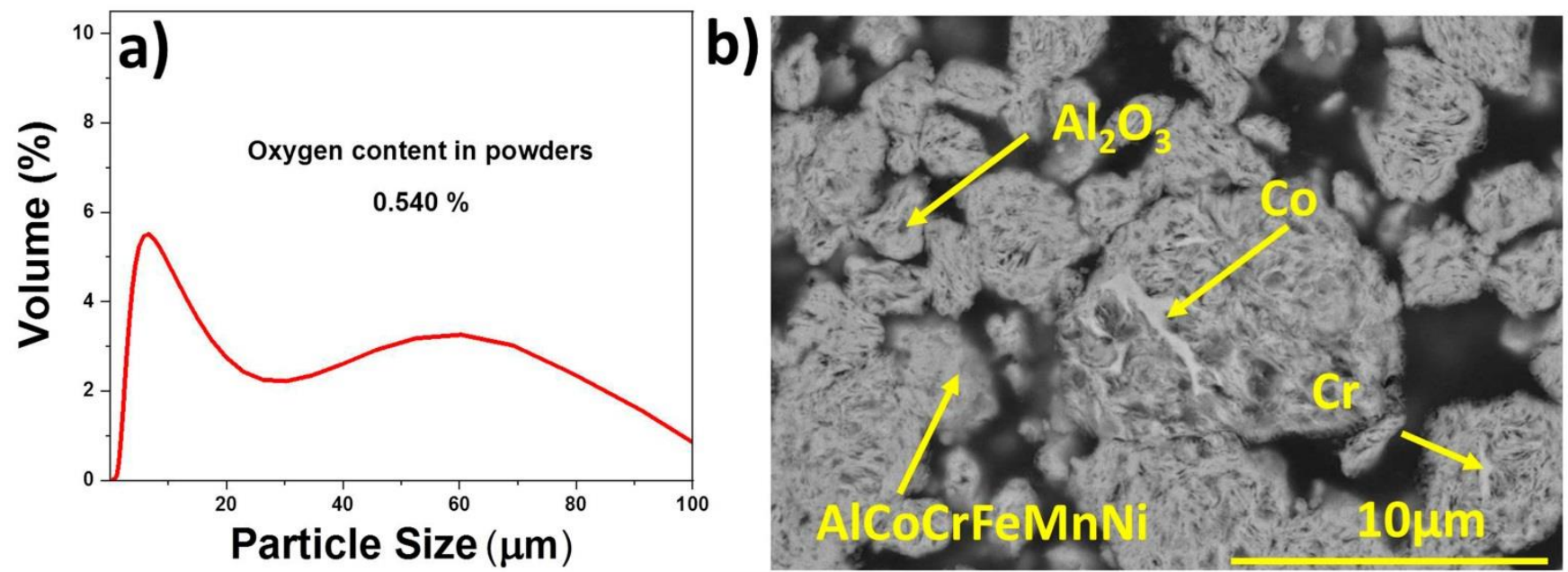

Figure 1. Figure 1. Alloyed powder characterization a) Particle size distribution (PSD) and oxygen content, b) cross-section micrograph (SEM-BSE).
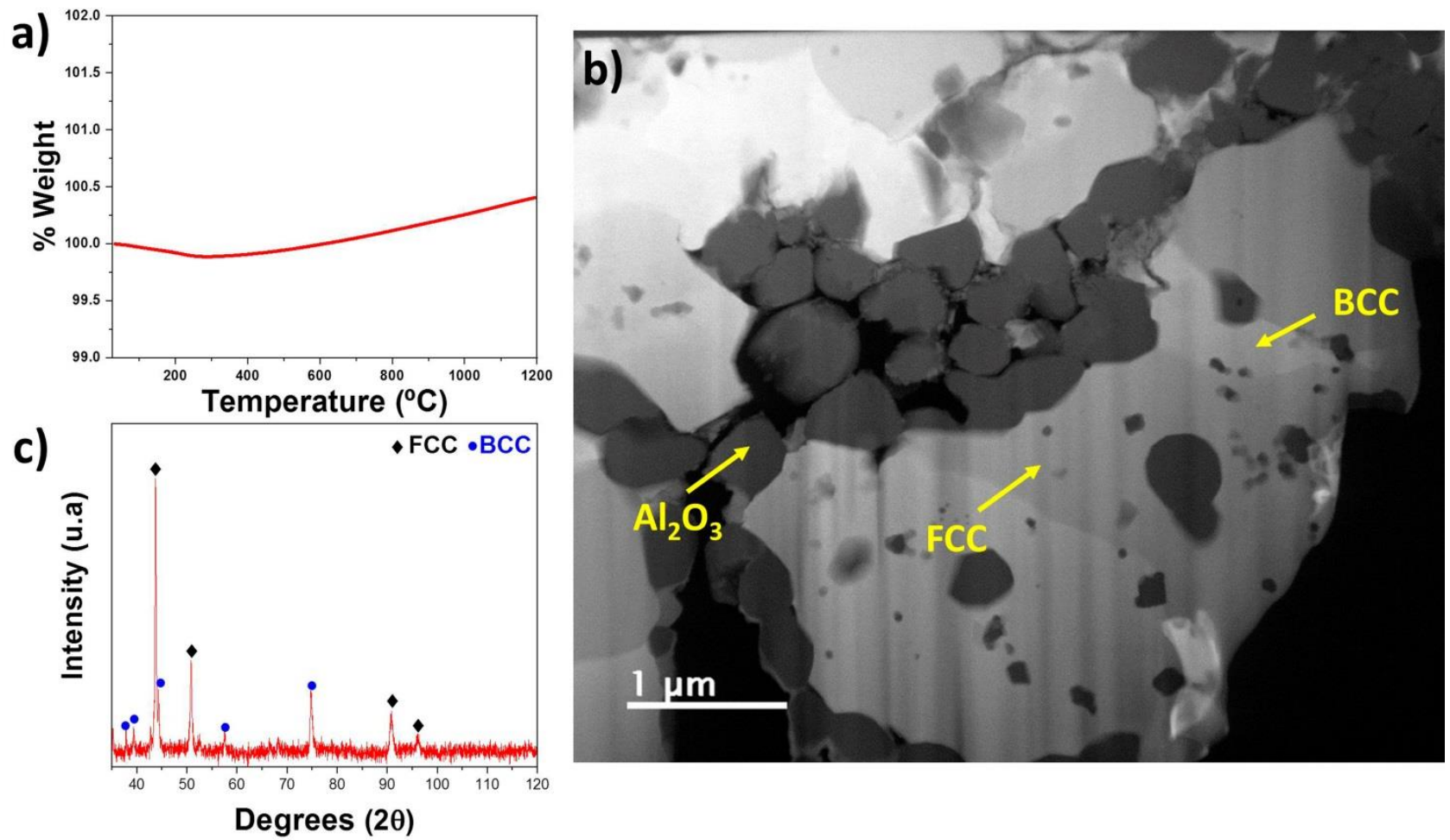

Figure 2. Figure 2. Sintered samples characterization a) thermogravimetric analysis (TGA), b) microstructure micrograph (STEM), and c) diffractogram obtained by XRD.

\section{References}

[1] L. Shaw, J. Villegas, H. Luo, M. Zawrah, and D. Miracle, Metallurgical and Materials Transactions. Volume 34 (2003), p. 159-170.

[2] Chao Wang, Wei Ji and Zhengyi Fu, Advanced Powder Technology Volume 25 (2014), p. 1334-1338. 